\title{
USO DEL ENSILADO BIOLÓGICO DE RESIDUOS DE PESCADO EN LA ALIMENTACIÓN DE CONEJOS
}

\author{
Graciela Yamada A. , Felipe San Martín H. ${ }^{2}$, Víctor Bazán R. $^{3}$ y Teresa Arbaiza F. ${ }^{2}$
}

\section{Wutwet}

The effect of feeding a biological silage composed of fish residue (SF) on growth and finishing of rabbits is examined. Ten experimental units, each comprised of 5 male and 5 female weaned 30 day old California breed rabbits were established. Four diets were compared; treatment with $0 \% \mathrm{SF}(0 \mathrm{SF}), 30 \% \mathrm{SF}(30 \mathrm{SF}), 50 \% \mathrm{SF}(50 \mathrm{SF})$ and $70 \% \mathrm{FS}(70 \mathrm{SF})$, and data on production parameters recorded. Daily weight gain ( $\mathrm{g}$ ), feed consumption $(\mathrm{kg})$, food convertion index and feeding $\operatorname{cost}(\mathrm{S} /$ ), were: $18.51,5.18,5.01$ and 2.75 for $0 \mathrm{SF}$; $19.68,5.54,5.09$ and 2.91 for $30 \mathrm{SF} ; 17.64,5.29,5.63$ and 3.40 for $50 \mathrm{SF}$; and $12.03,5.27,9.70$ and 5.59 for 70 SF, respectively. The only statistically significant variation $(\mathrm{p}<0.05)$ was found in the reduced yields produced by the $70 \mathrm{SF}$ treatment. The least expensive feeding alternative was a diet of $70 \%$ bran and $30 \%$ alfalfa, although the use of upto $30 \% \mathrm{SF}$ produces improvements in daily of weight gain.

Key words: Fish residue biological silage, feeding rabbits, feeding cost.

\section{momiter}

El presente experimento tuvo como objetivo evaluar el efecto del Ensilado Biológico de residuos de pescado (EP) en la dieta para crecimiento y acabado de conejos. El experimento consistió en dos ensayos utilizando conejos de la raza californiana destetados a los 30 dias de edad. Se compararon cuatro dietas; tratamiento con $0 \%$ de EP (0EP), $30 \%$ de EP (30EP), 50\% de EP (50EP) y 70\% de EP (70EP). Se midió la ganancia diaria de peso, consumo de alimento, índice de conversión alimenticia y costo de alimentación. El diseño fue en bloques al azar con cuatro tratamientos. Cada experimento tuvo 10 unidades experimentales (cinco hembras, cinco machos). La ganancia diaria de peso (g), consumo de alimento $(\mathrm{kg})$, índice de conversión alimenticia y el costo de alimentación $(\mathrm{S} /$ ) fueron: para 0EP de $18.51,5.18,5.01$ y $2.75 ; 30 \mathrm{EP}$ de $19.68,5.54,5.09$ y $2.91 ; 50 \mathrm{EP}$ de $17.64,5.29,5.63$ y $3.40 ; 70 \mathrm{EP}$ de $12.03,5.27,9.70$ y 5.59 , respectivamente, existiendo una menor respuesta biológica $(\mathrm{p}<0.05)$ en el tratamiento $70 \mathrm{EP}$ con respecto a los demás tratamientos. Se concluye que la alternativa con $70 \%$ de afrecho y $30 \%$ de heno de alfalfa da lugar a menores costos alimenticios. Asi mismo el uso de EP hasta un nivel del $30 \%$ produce mejoras en la ganancia diaria de peso, siendo contraproducente su inclusión en un nivel de $70 \%$ en la ración para conejos.

Palabras clave: Ensilado biológico de residuos de pescado, alimentación de conejos, costo de alimentación.

\footnotetext{
'Práctica privada

${ }^{2}$ Laboratorio de Bioquimica y Nutrición - FMV - UNMSM. Apdo. 41-0068. Lima-Perú.

${ }^{3}$ Laboratorio de Producción Animal
} 
inkutirontin

El conejo (Oryctolagus cuniculus), es una especie de fácil manejo cuya carne presenta características poco conocidas; como son el alto contenido de proteínas y la baja cantidad de grasas, en comparación con el ave, vacuno, porcino e incluso el cuy. Estas propiedades le dan a esta especie ventajas para servir como complemento de la alimentación proteica de la población de nuestro país.

Pocos son los trabajos en nuestro país sobre la alimentación de conejos; sin embargo, el alto costo de los alimentos concentrados comerciales, hacen que los productores opten por una alimentación tradicional, con el consiguiente atraso en el crecimiento y acabado de los animales.

En la actualidad, debido a la libre competencia en el mercado se busca obtener mayores rendimientos a bajo costo, siendo una alternativa alimenticia en la crianza del conejo el empleo de subproductos agrícolas e industriales que no compiten con la alimentación humana. Uno de los subproductos industriales que existe en nuestro medio y que en muchos de los casos se convierte en un contaminante de las aguas de nuestro litoral, lo constituye el residuo de la industria pesquera: Vísceras, cola, cabeza, pescados varios y otras especies marinas que no tienen aceptación y/o no son aptas para el consumo humano. Estos residuos poseen un contenido proteico casi como los filetes de pescado, pero tienen la particularidad de sufrir rápidos procesos de alteración, produciendo malos olores y problemas de polución y contaminación ambiental. Estos desechos industriales, con la aplicación de procesos químicos con ácidos orgánicos e inorgánicos o un proceso biológico con el uso bacterias lácticas homofermentadoras del yogurt, dan como resultadoel ensilado de pescado (Berenz, 1996).

\section{Ensilado Biológico de Residuos de Pes- cado (E.P)}

El ensilado biológico de residuos de pescado es un producto de fácil elaboración y de bajo costo; contiene desechos de la industria pesquera que no tienen aceptación y/o no son aptas para el consumo humano, que sometidos a un proceso de fermentación controlada por bacterias lácticas $y$ carbohidratos, favorece la proteólisis de los residuos de pescado, obteniéndose un producto acidificado muy estable y de buenas cualidades nutritivas (Berenz, et al., 1994). Las cualidades nutritivas del ensilado se refuerzan debido a que este insumo no es afectado por el calor, no requiere secado como en la harina de pescado, lo que abarata su producción, y es de fácil mezclado con insumos secos como maíz, afrecho, arroz y otros. Otra característica del ensilado biológico de residuos de pescado es que presenta bacterias conocidas por sus propiedades beneficiosas en el tracto intestinal, junto a las sustancias que se generan contra las bacterias patógenas y putrefactivas resultando de gran utilidad en dietas para animales (Berenz,1996).

\section{Procesamiento del Ensilado Biológico de Residuos de Pescado}

El ensilado biológico de pescado es el producto de la mezcla de los residuos de pescado cocido y molido, bacterias del yogurt (Lactobacillus bulgaricus y Streptococcus thermophylus), azúcar de caña como sustrato fermentable incubado por 48 horas a una temperatura optima de $40^{\circ} \mathrm{C}$ (Areche, et al. 1989), sin embargo las bacterias pueden actuar a una temperatura menor de 30 grados, pero en este caso la fermentación será más lenta. Durante la fermentación las bacterias lácticas se incrementan de $10^{6} \mathrm{col} /$ g a $10^{9} \mathrm{col} / \mathrm{g}$, en cambio las bacterias putrefactivas se mantienen en niveles de $10^{4}$ $\mathrm{col} / \mathrm{g}$. Las bases volátiles nitrogenadas e histaminas, se encuentran en bajos niveles y el producto puede durar hasta 6 meses a temperatura de ambiente, principalmente por que las bacterias putrefactivas productoras de histaminas están limitadas por la cocción inicial y el pH obtenido (Berenz, 1996).

El presente estudio evalúa la utilización del ensilado de pescado como insumo 
proteico-energético de origen marino en la alimentación de los conejos.

\section{Mererales y Wignos:}

El proyecto se realizó en la unidad de producción de conejos del Laboratorio de Producción Agropecuaria y en el Laboratorio de Bioquímica, Nutrición y Alimentación animal de la Facultad de Medicina Veterinaria de la Universidad Nacional Mayor de San Marcos.

Se utilizaron 40 conejos de la raza california machos y hembras, de 30 días de edad, recién destetados. Los conejos luego de pesados y sexados fueron distribuidos al azar en 4 tratamientos de 10 animales cada uno ( 5 hembras y 5 machos). Los animales fueron llevados a jaulas individuales de $50 \mathrm{~cm}$ de largo por $40 \mathrm{~cm}$ de ancho, provistos de bebederos y comederos de arcilla; a cada animal se le asignó un número en la jaula para su identificación.
Los insumos utilizados para la alimentación de los animales fueron: heno de alfalfa, afrecho y ensilado biológico de residuos de pescado (EP); los cuales fueron adquiridos en una cantidad suficiente para evitar variaciones en la composición de las raciones. Estos insumos fueron sometidos a un análisis proximal al inicio del experimento.

La ración diaria por animal y por tratamiento fue distribuida durante las mañanas a razón de $100 \mathrm{~g}$ por animal, el EP y afrecho se mezclaron diariamente y se pesaron al momento de la administración al igual que el heno de alfalfa. Los residuos de alimento fueron pesados todos los días y el cambio de agua fue diario.

Cada 7 días se realizaba el pesaje de los animales de cada tratamiento. Los pesos fueron registrados durante las ocho semanas que duró el experimento.

\section{Tratamientos:}

En el Cuadro 1 se describen los tratamientos utilizados en el estudio.

Cuadro 1. Descripción de los tratamientos.

\begin{tabular}{lclll}
\hline \multirow{2}{*}{ Insumos } & \multicolumn{4}{c}{ Tratamientos* } \\
\cline { 2 - 5 } & $0 \mathrm{EP}$ & $30 \mathrm{EP}$ & $50 \mathrm{EP}$ & $70 \mathrm{EP}$ \\
\hline & & & \\
Ensilado de pescado (EP) & $0 \mathrm{~g}(0)$ & $21 \mathrm{~g}(30)$ & $35 \mathrm{~g}(50)$ & $49 \mathrm{~g}(70)$ \\
Afrecho (A) & $70 \mathrm{~g}(100)$ & $49 \mathrm{~g}(70)$ & $35 \mathrm{~g}(50)$ & $21 \mathrm{~g}(30)$ \\
Heno de alfalfa (Ha) & $30 \mathrm{~g}$ & $30 \mathrm{~g}$ & $30 \mathrm{~g}$ & $30 \mathrm{~g}$
\end{tabular}

$0 \mathrm{EP}=\mathrm{A}$ más Ha y $0 \%$ de EP en la mezcla $\mathrm{EP}$ y A; $30 \mathrm{EP}=30 \%$ de EP en la mezcla de EP-A más Ha; $50 \mathrm{EP}=50 \%$ de EP en la mezcla de EP-A más Ha; 70EP $=70 \%$ de EP en la mezcla de EP-A más Ha.

En el Cuadro 2 se presenta la calidad nutritiva de los insumos y las dietas experimentales (tratamientos).

\section{Parámetros Evaluados:}

Para determinar el nivel de aceptación de cada tratamiento se tomaron como referencia los consumos diarios de cada animal durante los primeros siete días.
Se tomaron los registros individuales de peso vivo de los animales de cada tratamiento al inicio del experimento y cada 7 días hasta la octava semana (56 días). A partir del peso semanal se estimó la ganancia diaria de peso vivo mediante regresión lineal $\mathrm{Y}=\mathrm{a}+\mathrm{bx}$; donde $\mathrm{Y}$ es el peso vivo en $\mathrm{kg}$, a el intercepto, $x$ la variable independiente (días) y $b$ la pendiente que indica la ganancia diaria de peso. Así mismo 
Cuadro 2. Análisis proximal de los insumos, alimento comercial y mezclas de EP-A empleados (\%).

\begin{tabular}{lccccccc}
\hline & Humedad & Base seca & Proteína & $\begin{array}{c}\text { Extracto } \\
\text { Etéreo }\end{array}$ & $\begin{array}{c}\text { Fibra } \\
\text { Cruda }\end{array}$ & Ceniza & $\begin{array}{c}\text { Extracto } \\
\text { Libre de } \\
\text { Nitrógeno }\end{array}$ \\
\hline Ens. Pescado (EP) & 60.0 & 40.0 & 53.2 & 4.9 & 0 & 21.6 & 20.3 \\
Afrecho & 8.5 & 91.4 & 17.6 & 4.5 & 7.9 & 5.3 & 64.7 \\
Heno alfalfa & 7.5 & 92.5 & 16.1 & 1.7 & 22.4 & 9.9 & 49.8 \\
30EP & 24.0 & 76.0 & 24.1 & 5.4 & 8.8 & 10.4 & 51.3 \\
50EP & 34.9 & 65.1 & 27.9 & 4.8 & 5.8 & 11.7 & 50.0 \\
70EP & 43.3 & 56.7 & 31.2 & 4.6 & 4.7 & 11.9 & 47.5 \\
\hline
\end{tabular}

se evaluó la ganancia diaria durante los 56 días y entre los periodos 0 a 28 y 29 a 56 días.

El consumo de alimento diario se obtuvo por diferencias entre el alimento ofrecido y el residuo de alimento de día siguiente; este consumo se midió por tratamiento entre 0 a 56 días, 0 a 28 días y 29 a 56 días. Con esta información se determinó el índice de conversión alimenticia por tratamiento, durante dichos períodos.

Para el cálculo del índice de conversión alimenticia (ICA) se utilizó la siguiente fórmula (De Blas, 1989):

\section{ICA $=$ Consumo de alimento $(\mathrm{kg})$ Diferencia de peso vivo $(\mathrm{kg})$}

Con la ayuda de estas mediciones se determinó el costo de alimentación usándose la siguiente fórmula (De Blas, 1989):

Costo de alimentación: Consumo de alimento $(\mathrm{kg}) \times$ Precio por $\mathrm{kg}$ de alimento $(\mathrm{S} /$.$) \times Ganancia de peso vivo (\mathrm{kg})^{-1}$

El diseño experimental usado fue el de bloques (sexo) al azar. Cada tratamiento contó con diez unidades experimentales. La ganancia de peso, consumo de alimento y el índice de conversión alimenticia fueron eva- luados mediante el análisis de varianza y la prueba DMS protegida (Steel y Torrie, 1990).

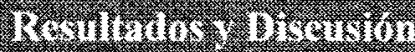

Los resultados sobre la ganancia de peso se presentan en el Cuadro 3, se ha considerado la ganancia de peso para los períodos de 0 a 28 días, 29 a 56 días y por último el período total de 0 a 56 días. En el primer período ( 0 a 28 días) se observa un ligero incremento por la inclusión del $30 \%$ de EP para luego decaer ( $p>0.05$ ) en los tratamientos con $50 \%$ y $70 \%$ de EP.

Durante el segundo período ( 29 a 56 días), se observa una drástica caida en la ganancia de peso en el tratamiento con $70 \%$ de EP. Por último, al considerar todo el período ( 0 a 56 días) sólo se observa una significativa menor ganancia de peso $(\mathrm{p}<0.05)$ en el tratamiento con $70 \%$ de EP.

La inclusión de EP, producto de un alto contenido proteico de alto valor biológico, pero de carácter acuoso, mejora el balance nutricional de la dieta base. Así, se observa que la inclusión de un $30 \%$ de EP produce una mayor respuesta en la ganancia de peso del conejo, pero que sin embargo inclusiones del $70 \%$ de EP se traduce en ganancias sumamente bajas. 
Cuadro 3. Pesos, ganancia diaria de peso, consumo de alimento, indice de conversión alimenticia y costos de alimentación por tratamiento.

\begin{tabular}{|c|c|c|c|c|c|}
\hline & \multicolumn{5}{|c|}{ Tratamientos * } \\
\hline & $0 \mathrm{EP}$ & $30 \mathrm{EP}$ & $50 \mathrm{EP}$ & $70 \mathrm{EP}$ & EEM \\
\hline Peso vivo inicial, $\mathrm{kg}$ & 0.84 & 0.82 & 1.04 & 1.02 & \\
\hline Peso vivo final, $\mathrm{kg}$ & 1.90 & 1.93 & 1.99 & 1.60 & \\
\hline \multicolumn{6}{|l|}{ Ganancia diaria de peso, $\mathrm{g}$} \\
\hline 0 a 28 días & $21.58^{\mathrm{a}, \mathrm{b}}$ & $25.18^{b}$ & $19.05^{\mathrm{a}}$ & $17.59^{\mathrm{a}}$ & 2.964 \\
\hline 29 a 56 días & $15.83^{\mathrm{a}}$ & $15.74^{\mathrm{a}}$ & $14.53^{\mathrm{a}}$ & $4.35^{\mathrm{b}}$ & 3.574 \\
\hline 0 a 56 días & $18.5 \mathrm{l}^{\mathrm{a}}$ & $19.68^{\mathrm{a}}$ & $17.64^{\mathrm{a}, \mathrm{b}}$ & $12.03^{b}$ & 4.176 \\
\hline \multicolumn{6}{|l|}{ Consumo de alimento, $\mathrm{kg}$} \\
\hline 0 a 28 días & $2.45^{\mathrm{a}}$ & $2.74^{\mathrm{a}}$ & $2.52^{\mathrm{a}}$ & $2.52^{\mathrm{a}}$ & 0.368 \\
\hline 29 a 56 días & $2.73^{\mathrm{a}}$ & $2.80^{\mathrm{a}}$ & $2.77^{\mathrm{a}}$ & $2.72^{\mathrm{a}}$ & 0.088 \\
\hline 0 a 56 días & $5.18^{\mathrm{a}}$ & $5.54^{\mathrm{a}}$ & $5.29^{\mathrm{a}}$ & $5.27^{\mathrm{a}}$ & 0.421 \\
\hline \multicolumn{6}{|l|}{ Conversión alimenticia (ICA) } \\
\hline 0 a 28 días & $4.06^{\mathrm{a}}$ & $4.04^{\mathrm{a}}$ & $4.83^{\mathrm{b}}$ & $5.53^{\mathrm{c}}$ & 0.346 \\
\hline 29 a 56 días & $6.09^{\mathrm{a}}$ & $7.06^{\mathrm{a}}$ & $7.08^{\mathrm{a}}$ & $13.07^{\mathrm{a}}$ & 23.274 \\
\hline 0 a 56 días & $5.03^{\mathrm{a}}$ & $5.09^{\mathrm{a}}$ & $5.63^{\mathrm{a}}$ & $9.70^{b}$ & 1.990 \\
\hline Costo de alimentación, $\mathrm{S} /$ & 2.75 & 2.91 & 3.40 & 5.59 & \\
\hline Precio por kg de alimento, $\mathrm{S} /$ & 0.56 & 0.58 & 0.61 & 0.62 & \\
\hline
\end{tabular}

* Letras diferentes en cada fila indican diferencias significativas entre tratamientos a la prueba de análisis de varianza $(\mathrm{P}<0.05)$.

$E E M=$ Error estándar de la media.

Si bien se ha probado con éxito en cerdo niveles altos de EP, este ensayo indica que niveles del $70 \%$ en conejos se traduce en menores rendimientos en términos de ganancia de peso lo que podría explicarse a la sensibilidad de los conejos a la acidez de este producto (Tatterson y Potter, 1991).

Con respecto al consumo no se obtuvo diferencias entre tratamientos $(\mathrm{p}>0.05)$ en ninguno de los períodos. Si bien la literatura indica que el olor a fruta fermentada del EP determina una mayor preferencia del alimento (Areche, et al., 1994), aparentemente este factor no tuvo efecto en el consumo del alimento sugiriendo la poca relevancia que tiene el aroma o el olor en el nivel de consumo por parte del conejo.
Por otro lado, debido a la pobre ganancia de peso en los animales que recibieron el tratamiento con $70 \%$ de EP, el índice de conversión alimenticia fue mayor, en casi el doble ( $p>0.05$ ), al de los otros tratamientos.

El precio por kg de alimento fue superior a medida que se incrementaban los niveles de EP. Por otro lado, sumado a los rendimientos en términos de ganancia de peso, los costos de producción llegaron a duplicarse cuando se incluyó $70 \%$ de EP en la ración. En resumen, niveles de EP superiores a 50\% afectaron significativamente los costos de producción por lo que debería recomendarse niveles menores al $30 \%$ de EP en la dieta de conejos. 


\section{Bitorima chews}

1. Areche, T.; Nicanor, Z. Berenz y G León.1989. Inocuidad del ensilado de pescado en la producción del vómito negro. Boletín de investigación del Instituto Tecnológico Pesquero del Perú. p.37.

2. Areche T.; Nicanor, Z. Berenz y G León.1994.Utilización del Ensilado de Residuos de Pescado en dietas para Cerdos. Boletín de Investigación del Instituto Tecnológico Pesquero del Perú. 4:7790.

3. Berenz, Z. 1996. Instituto tecnológico pesquero del Perú - Curso internacional sobre procesamiento pesquero para la seguridad alimentaria ensilado a partir de residuos de pescado Callao - Perú.
4. Berenz, Z.; F. Romero y G Beoutis. 1994. Utilización de Ensilados de Residuos de Pescado en dietas para pollos de carne. Boletín de Investigación del Instituto Tecnológico Pesquero del Perú. 4:91.

5. Mossel, D. 1971. Phisiological and metabolic atributes of microbial groups associated with food.J. Appl.Bact. 34:126-142.

6. Steel, R.G.D. y J.H. Torrie. 1990. Bioestadística:Principios y Procedimientos. Segunda Edición. McGrawn Hill. México. $238 \mathrm{p}$.

7. Tatterson I.N. y D.P. Potter. 1991. Curso Internacional de Tecnología de Productos Pesqueros - sub productos de pesquería. Chile. $2-13$ p. 